Published in final edited form as:

Drug Discov Today. 2019 May ; 24(5): 1139-1147. doi:10.1016/j.drudis.2019.03.013.

\title{
New targets for HIV drug discovery
}

\author{
Ana C. Puhl ${ }^{1}$, Alfredo Garzino Demo ${ }^{2,3,4}$, Vadim A. Makarov ${ }^{5}$, and Sean Ekins ${ }^{1, *}$ \\ ${ }^{1}$ Collaborations Pharmaceuticals, Inc., Main Campus Drive, Lab 3510 Raleigh, NC 27606, USA \\ 2Department of Microbiology and Immunology, University of Maryland, School of Medicine, \\ Baltimore, Maryland, USA \\ ${ }^{3}$ Institute for Human Virology, University of Maryland, School of Medicine, Baltimore, Maryland, \\ USA \\ ${ }^{4}$ Department of Molecular Medicine, University of Padova, Padova, Italy \\ ${ }^{5}$ Bach Institute of Biochemistry, Research Center of Biotechnology of the Russian Academy of \\ Sciences, Leninsky Prospekt 33-2, Moscow, 119071, Russia
}

\begin{abstract}
Recent estimates suggest close to one million people per year die globally owing to HIV-related illnesses. Therefore, there is still a need to identify new targets to develop future treatments. Many of the more recently identified targets are host-related and these might be more difficult for the virus to develop drug resistance to. In addition, there are virus-related targets (capsid and RNAse H) that have yet to be exploited clinically. Several of the newer targets also address virulence factors, virus latency or target persistence. The targets highlighted in this review could represent the next generation of viable candidates for drug discovery projects as well as continue the search for a cure for this disease.
\end{abstract}

\section{Keywords}

Drug discovery; HIV; host targets; virus targets; drug candidates

\section{Introduction}

AIDS, caused by HIV, was first recognized as a new disease in 1981 and is still one of the most significant pathogens affecting humankind [1]. Numbers published by the WHO are particularly bleak. It has claimed $>35$ million lives globally, and 940000 people died of

\footnotetext{
*Corresponding author: Ekins, S. (sean@ collaborationspharma.com).

Publisher's Disclaimer: This is a PDF file of an unedited manuscript that has been accepted for publication. As a service to our customers we are providing this early version of the manuscript. The manuscript will undergo copyediting, typesetting, and review of the resulting proof before it is published in its final citable form. Please note that during the production process errors may be discovered which could affect the content, and all legal disclaimers that apply to the journal pertain.

Teaser:We describe more than 20 targets that can be addressed by small-molecule treatments that could overcome HIV drug resistance as well as provide a potential cure.

Conflicts of interest

A.C.P. is an employee and S.E. is owner of Collaborations Pharmaceuticals. The content is solely the responsibility of the authors and does not necessarily represent the official views of the National Institutes of Health.
} 
HIV-related illnesses in 2017 alone [2]. Currently, approved HIV drugs target reverse transcriptase (RT), HIV protease and integrase, the $\mathrm{C}-\mathrm{C}$ motif chemokine receptor type 5 (CCR) found on the host cells [3], as well as the process of membrane fusion. HIV can be managed, albeit with a cocktail of 2-4 antiretroviral drugs that need to be taken regularly. Side effects are a concern for these drugs that need to be taken for decades now that it is treated as a chronic disease [4]. Also, many patients develop HIV-associated neurological dysfunctions, resulting in a range of cognitive and motor function deficits [5,6]. Virus can remain in the central nervous system (CNS) and replicate, which then results in the neurological disorders. This could be caused by the inability of HIV medications to cross the blood-brain barrier (BBB) [7] and inhibit HIV in the brain, which is crucial to reverse or improve HIV-associated neurocognitive disorder [8,9]. Although it is possible to improve on known classes of drugs such as the RT inhibitors [10], these continuing liabilities of current HIV treatments suggest that it is important to find drugs that can intervene at other targets whether against host or virus. The following represents a selection of predominantly newer promising targets (Table 1) that have already been modulated by small molecules or for which crystal structures are available.

\section{Host dependency factors TPST2, SLC35B2 and ALCAM}

Because HIV relies on host proteins for entry, replication and transmission, the identification of new host dependency factors (HDFs) might result in a higher barrier to drug resistance [11] and lead to curative interventions [12,13]. Host proteins hijacked by pathogens are often used for essential cellular functions such as transcription and translation once inside the cell $[14,15]$, whereas host factors used for pathogen entry are often dispensable for cell viability, as is the case for CCR5. A CRISPR screen conducted in a $\mathrm{CD} 4^{+} \mathrm{T}$ cell leukemia line identified host factors required for productive HIV infection: TPST2, SLC35B2 and ALCAM, which were not identified in earlier genome-wide searches [16]. These highlight sulfation on the HIV co-receptor CCR5 and T cell aggregation as potential targets for therapeutic intervention. The importance of sulfated tyrosines as a contribution factor to the binding of CCR5 to macrophage inflammatory protein (MIP)- $1 a$, MIP- $1 \beta$ and HIV-1 glycoprotein 120 (gp120)-CD4 complexes and to the ability of HIV-1 to enter cells expressing CCR5 and CD4, was described almost 20 years ago [17]. CXCR4, another important HIV-1 coreceptor, is also sulfated [17].

Activated sulfate in the form of $3^{\prime}$-phosphoadenosine $5^{\prime}$-phosphosulfate (PAPS) is needed for all sulfation reactions in eukaryotes [18]. The adenosine PAPS transporter 1, encoded by the gene $S L C 35 B 2$, transports the activated sulfate donor PAPS from the cytosol into the Golgi lumen [19]. The protein-tyrosine sulfotransferase 2, encoded by the gene TPST2, then catalyzes O-sulfation on the tyrosines of secretory and plasma membrane proteins [20]. Importantly, TPST2 sulfates the N-terminal residues on CCR5 that are known to mediate interactions with the HIV envelope gp120 and also sulfates key tyrosine residues on CXCR4 - the other major co-receptor for HIV; and these tyrosine residues on CXCR4 are known to mediate important interactions with HIV gp120. In the same CRISPR screen study, the authors also demonstrated that loss of the cell adhesion molecule ALCAM (a cell surface protein expressed on activated immune cells) prevents the spread of HIV infection and might be a host target for HIV [16]. 


\section{Targeting Gag cleavage proteins, capsid and cyclophilin A}

Because capsid assembly and disassembly finely regulates HIV-1 replication, it represents an emerging and attractive target [21]. HIV Gag protein cleavage into its two structural proteins, matrix (MA) and capsid (CA), can dramatically affect viral production. MA- and CA-specific inhibitors have recently been identified using a HTS of 24000 compounds [22]. Screening based on the inhibition of capsid assembly and virtual screening for molecules binding to the capsid has successfully identified several potential small-molecule compounds [23]. Bevirimat, a plant-derived natural product, had been originally identified as a weak inhibitor of HIV-1 replication and has been tested in a clinical trial Phase II, where it caused a significant viral load reduction [24]. The mechanism of action of the previously reported capsid-targeting HIV-1 inhibitor Boehringer-Ingelheim compound 1 (C1) was described, showing that $\mathrm{C} 1$ acts during HIV-1 maturation to prevent assembly of a mature viral capsid. However, unlike the maturation inhibitor bevirimat, $\mathrm{C} 1$ did not significantly affect the kinetics or fidelity of Gag processing [25]. In another study, a series of inhibitors bound to the N-terminal domain of CA [26] showed that these inhibitors induce the formation of a pocket that overlaps with the binding site for the previously reported CAP inhibitors but is expanded significantly by these new, more-potent CA inhibitors.

The host cell protein cyclophilin A (CypA) binds directly to the HIV-1 capsid and modulates capsid uncoating and viral infectivity. Interference with CypA binding inhibits HIV-1 replication in cell culture [27]. A series of thiourea compounds as HIV-1 assembly and disassembly dual inhibitors was designed and synthesized targeting HIV-1 CA protein and human CypA. The results suggested that 15 compounds could block HIV-1 replication by inhibiting the peptidylprolyl cis-trans isomerase (PPIase) activity of CypA to interfere with capsid disassembly and disrupting CA assembly [28]. The structure of CypA in complex with an HIV-1 capsid tubular assembly was determined at $8 \AA$ resolution by cryoEM and revealed a novel, noncanonical, second capsid-binding site on CypA that is vital for stabilizing the viral capsid [29]. The novel interaction interface of CypA could provide a new avenue for the development of therapeutic interventions that target CypA interactions with the HIV-1 capsid [29].

\section{Protein disulfide isomerase and galectin-9}

Protein disulfide isomerase (PDI) is a $57 \mathrm{kDa}$ oxidoreductase of the thioredoxin superfamily that is expressed mainly in the endoplasmic reticulum (ER) of eukaryotic cells. In the ER, it catalyzes the rearrangement of incorrect disulfide bonds through isomerase activity, thus mediating proper protein folding [30]. PDI, together with additional ER secretory proteins, can be secreted to the cell surface through a regulatory pathway. PDI-catalyzed reduction of disulfides in gp120 has been shown to be crucial for HIV-1 entry into host cells [31,32]. Several agents have been described as PDI inhibitors, although none has been used therapeutically $[31,33]$ owing to their nonspecific activities and toxicities. The discovery of a sesquiterpenoid juniferdin and an analog showed specific inhibition of PDI reductase activity and did not inhibit the other homologs of PDI [34]. Hence, their ability to inhibit the PDI-catalyzed reduction of HIV gp120 suggests they might be promising as inhibitors of viral entry. Recently, researchers reported that a sugar-binding protein called galectin- 9 traps 
PDI on the surface of T cells making them more susceptible to HIV infection [35]. It was demonstrated that galectin- 9 enhances HIV-1 infection of T cells in a PDI-dependent manner [35].

\section{CD4 mimics}

Several groups have reported the discovery and design of small-molecule CD4 mimics targeting the Phe 43 cavity of HIV-1 envelope glycoprotein gp120, as entry inhibitors [36,37]. One of these groups proposed compounds with IC50 values as low as $150 \mathrm{nM}$. These compounds also inhibited cell-cell fusion and cell-cell HIV-1 transmission [36].

\section{BRAF histone deacetylase complex 80}

Efficient HIV-1 transcription from HIV-1 long terminal repeat (LTR) requires host cell factors and HIV-1 Tat protein [38]. The Tat protein plays an indispensable part in HIV reactivation, and histone demethylase (LSD1) promotes Tat-mediated LTR activation. BRAF-histone-deacetylase complex 80 (BHC80) is key for LSD1-triggered LTR activation. The LSD1-BHC80 complex enhances HIV-1 transcription by decreasing histone H3 lysine 4 trimethylation at the viral promoter [39] and it might be used as a new drug target to reactivate latent HIV-1.

\section{Protein phosphatase 1}

HIV-1 transcription is regulated by host cell protein phosphatase-1, it is sensitive to the reduction of intracellular iron which affects cell-cycle-dependent kinase 2 [38] and can be modulated via small-molecule inhibitors, iron chelating compounds and curcumin analogs [40].

\section{RNAse H}

The RNase H active site of HIV-1 RT has no approved therapeutics. Recent work has described inhibitors that chelate with magnesium ions and inhibit site-specific cleavage responsible for initiating the second strand of viral DNA synthesis [41]. The development of dual inhibitors of IN/RNAse $\mathrm{H}$ is an attractive strategy for drug development, because they are selective targets for HIV-1 chemotherapy [42]. Recently, it was demonstrated that a pyrazolecarbothioamide derivative was able to inhibit viral replication and $\mathrm{RNase} \mathrm{H}$ and RNA-dependent DNA polymerase (RDDP) RT-associated activities in the low micromolar range [43].

\section{LEDGF/p75}

Lens epithelium-derived growth factor p75 (LEDGF/p75) is an epigenetic reader, transcriptional coactivator and attractive therapeutic target involved in HIV integration. It has a role in tethering protein complexes to chromatin and is linked to multiple diseases such as HIV infection. It consists of a Pro-Trp-Trp-Pro (PWWP) domain and the integrasebinding domain (IBD), which is a target for inhibiting HIV [44]. 


\section{c-SRC protein tyrosine kinase}

Tyrosine kinases promote viral infection from the initial binding of viral gp120 to the T lymphocyte receptor CD4 and chemokine coreceptor CXCR4 (X4 viruses) or CCR5 (R5 viruses); however, non-receptor tyrosine kinases also have crucial roles during the early stages of the HIV-1 lifecycle in T cells [45]. The SRC tyrosine kinases become activated within minutes of HIV-1 infection on $\mathrm{CD}^{+}{ }^{+} \mathrm{T}$ cells [46]. c-SRC tyrosine kinase is a major regulator of HIV-1 infection, participating in multiple stages of infection post-entry. Decreasing c-SRC expression and/or activity provides a new target. Because there are already numerous kinase inhibitors, this suggests that some could be repurposed [47].

\section{Nef}

The viral protein Nef of HIV is a well-known virulence factor as well as a shuttling molecular adaptor that can affect infected and noninfected cells as well as having a key role on the chemocytokine network $[48,49]$. Nef can reduce cell surface expression of CD4, CD8, MHC-I, CD28, CD3 (HIV-2 and most SIVs), SERINC3/5 and/or CXCR4 to suppress antigen presentation, modulate $\mathrm{T}$ cell activation and promote efficient release of fully infectious virion. The reduction of the cell surface expression mediated by Nef occurs by simultaneous binding to the cytoplasmic domains of various receptors and clathrin-AP protein complexes $[49,50]$.

\section{Tat}

The early virus-encoded gene product Tat is required for robust transcription of the integrated viral genome by RNA polymerase II (RNAP II) [51] and is an attractive target for therapeutic intervention because it is expressed early during virus replication and it has no cellular homologs. Residual viremia is thought to be a major contributor to inflammation and other HIV-associated complications, leading to neurological and cardiovascular diseases [52]. Direct inhibition of Tat blocks the feedback loop that drives exponential increase in viral transcription and the production of viral particles [53]. In resting $\mathrm{CD} 4^{+} \mathrm{T}$ cells, HIV-1 is maintained in a latent state by several mechanisms, which include low levels of Tat [54] or active cellular protein kinase known as TAK (cyclin T1/PTEFb) [55], the exclusion of cellular transcription factors from the nucleus [56,57], the presence of repressors [58,59], transcriptional interference [60] and lower levels of intracellular deoxynucleoside triphosphate (dNTP) pools [61]. Transcriptional reactivation is accompanied by changes in the local chromatin structure, which is accomplished by recruitment via Tat of chromatin remodeling factors $[62,63]$ and histone acetyltransferases. Transcriptional silencing is a multifactorial phenomenon and the in vivo mechanisms of latency are still incompletely understood $[64,65]$.

It has been suggested that blocking Tat activity might help block viral reactivation and maintain the virus in a state of prolonged silencing $[53,66]$. Although dependence of HIV transcription on Tat has made it an attractive drug target, no approved Tat inhibitor therapeutics are currently available in the clinic. It was demonstrated that the Tat inhibitor didehydro-cortistatin A (dCA) prevents HIV-1 reactivation from latency [67]. The authors 
proposed that dCA treatment combined with antiretroviral treatment (ART) opens the possibility for culminating in a sterilizing cure, because it would delay or halt viral replication, reactivation and replenishment of the latent viral reservoir. Therefore, the latent pool of cells in an infected individual would be stabilized, and death of the long-lived infected memory $\mathrm{T}$ cells could result in a continuous decay of this pool over time [67]. The authors demonstrated the potential of this 'block-and-lock' functional cure approach based on properties of dCA [68]. Combining dCA with ART accelerates HIV-1 suppression and prevents viral rebound after treatment interruption, even during strong cellular activation in human $\mathrm{CD}^{+} \mathrm{T}$ cells isolated from aviremic individuals. Adding dCA to ART-suppressed mice systemically reduces viral mRNA in tissues, in the bone-marrow-liver-thymus (BLT) mouse model of HIV latency and persistence [68].

\section{Dendritic cell immunoreceptor}

The dendritic cell immunoreceptor (DCIR) is a C-type lectin receptor that is expressed on dendritic cells (DCs). DCIR acts as an attachment factor with HIV-1 and is directly involved in infection via transmission to $\mathrm{CD}^{+}{ }^{+} \mathrm{T}$ lymphocytes. Inhibitors that decrease HIV-1 attachment and propagation have recently been described [69], providing a potential approach for interference with the initial propagation of HIV-1 at an early stage of the viral cycle and limiting proliferation of the virus in the later stages.

\section{mTOR pathway}

mTOR inhibitors suppress HIV transcription through the viral transactivator Tat or via Tatindependent mechanisms. mTOR inhibitors Torin1 and pp242 suppressed the reactivation of latent $\mathrm{HIV}$ via $\mathrm{T}$ cell stimulants in the Bcl-2 HIV latency primary cell model and in $\mathrm{CD}^{+}{ }^{+} \mathrm{T}$ cells from patients on highly active antiretroviral therapy (HAART) [70]. Thus, the control of HIV latency by mTOR signaling suggests a pathway that could have therapeutic opportunities for HIV eradication [70,71].

\section{JAK pathway}

The JAK/STAT pathway is involved in HIV persistence. It was shown that the FDAapproved JAK inhibitors tofacitinib and ruxolitinib reduced the frequency of $\mathrm{CD} 4^{+} \mathrm{T}$ cells harboring integrated HIV DNA and targeted key events downstream of $\gamma$-C cytokine [interleukin (IL)-2, IL-7 and IL-15] ligation to their receptors, impacting the magnitude of the HIV reservoir in memory $\mathrm{CD}^{+}{ }^{+} \mathrm{T}$ cell subsets in vitro and ex vivo [72,73]. JAK inhibitors represent a therapeutic approach to prevent key events of $\mathrm{T}$ cell activation that regulate HIV persistence and this class of drugs has the advantage of also having been tested in clinical trials [73].

\section{Ku70}

$\mathrm{Ku} 70$ is a host protein that interacts with HIV integrase and can downregulate the polyubiquitination level and is required for early and late stages of the viral lifecycle. Ku70 can protect integrase from the host defense system and enable HIV-1 to hijack the host cell machinery. Interfering with Ku70 therefore disrupts HIV-1 replication [74]. 


\section{SIRT/AMPK pathway}

HIV-1 transcription is activated by the viral Tat protein which in turn is a substrate for the deacetylase activity of sirtuin 1 (SIRT1) [75]. Tat-mediated inhibition of the SIRT1 deacetylase and the resulting hyperactivation of nuclear factor $(\mathrm{NF}) \kappa \mathrm{B}$ function could thereby directly participate in the immune dysfunctions in infected patients [76]. AMPactivated protein kinase (AMPK) is activated by a decrease in cellular ATP levels $[77,78]$ and changes in AMPK activity (phosphorylation) are associated with alterations in SIRT1 abundance and activity. It was also demonstrated that Tat inhibited the AMPK signaling pathway through the NAD ${ }^{+} /$SIRT1 pathway. Both processes were involved in Tat-induced HIV-1 LTR transactivation. Hence targeting the SIRT1/AMPK pathway represents a new target for HIV intervention [79].

\section{Cytidine deaminases}

The APOBEC family of cytidine deaminases plays an important part in antiviral innate immunity. The APOBEC3 (A3) enzymes A3G and A3F are coordinately expressed in CD4 ${ }^{+}$ $\mathrm{T}$ cells and can become co-encapsidated into HIV-1 virions, primarily in the absence of the viral infectivity factor (Vif) [80]. These enzymes deaminate $\mathrm{dC}$ to $\mathrm{dU}$ in nascent minusstrand viral DNA, resulting in G-to-A hypermutation in the plus-strand DNA to inhibit the replication of HIV-1 [81]. Interestingly, the expression of APOBEC3G can be increased in cells by defensins and chemokines that bind to CCR6 $[82,83]$. Furthermore, there is some evidence that the CCR6 ligand human beta defensin 2 can induce the transition from highmolecular-mass APOBEC3G complexes to the low-molecular-mass monomeric form [83].

\section{Mucosa-associated lymphoid tissue translocation 1}

Mucosa-associated lymphoid tissue translocation 1 (MALT1) inhibitors are being aggressively pursued for treating lymphomas, which occur with high incidence in HIVinfected subjects, and there are several publications describing the repurposing of drugs that show MALT1 inhibition $[84,85]$. We (Lafferty and Garzino-Demo, unpublished results) are pursuing MALT1 inhibitors as part of a 'block and kill' strategy to a functional cure to HIV (i.e., suppression of reactivation and induction of apoptosis of infected cells). A publication on the effects of the MALT1 inhibitor: MI-2, on a cell line that is used as an in vitro model of HIV latency showed accelerated cell death in the presence of cell stimuli [86].

\section{Toll-like receptor 4}

Toll-like receptors (TLRs) are known as pattern recognition receptors (PRRs) where the specific level of action depends on the infecting pathogen and they have central roles in the innate immune system, representing the first line of defense [87,88]. Past studies have also shown the ability of TLR4 to lower HIV-1 replication [89]. The chemokine response triggered by the infectious agent upon interaction with the macrophages of the host and role in the containment of HIV-1 infection in the main targets of the virus, T cells and mononuclear phagocytes was demonstrated decades ago. LPS stimulates human monocytederived macrophages (MDM) to release soluble factors that strongly inhibit HIV replication, 
not only in macrophages but also in T lymphocytes [90]. Recombinant human RANTES, MIP-1 $\alpha$ and MIP-1 $\beta$ induced a dose-dependent inhibition of different strains of HIV-1, HIV-2 and simian immunodeficiency virus (SIV) [91]. Recently, a naturally derived polysaccharide peptide (PSP) from the fungus Coriolus versicolor [92] demonstrated antiHIV activity producing antiviral chemokines that block co-receptors. PSP also upregulated TLR4 expression [93].

\section{Y-box-binding protein 1}

The DNA and RNA binding protein Y-box-binding protein 1 (YB-1) has been associated with a plethora of viruses [94]. YB-1 was shown to form a complex with the HIV Tat-TAR transcriptional complex [95] supporting HIV replication. YB-1 is an important cofactor of HIV replication that exerts its effects at two stages in a concentration-dependent manner. The early effect occurs at a stage between reverse transcription and nuclear import. The late effect involves viral RNA stability and virus production. This could hence represent a new antiviral target that affects multiple stages of viral replication [96].

\section{B23/nucleophosmin}

B23/nucleophosmin (B23/NPM1) is a multifunctional protein constantly shuttling between the nucleus and cytosol. This influences viral replication because it has a role in nuclear import, viral genome transcription and assembly, as well as final particle formation. A small number of B23/NPM1 inhibitors are available as potential broad-spectrum antivirals [97].

\section{Natural seminal amyloids}

Small peptides present in human semen aggregate into amyloid-like fibrils and can increase infectivity by $>400000$ and can facilitate viral attachment and internalization. Interfering with these aggregates represents a potential target that could be used while also using other antiviral agents $[98,99]$. For example, the amyloid-binding benzothiazole aniline (BTA) molecules target $\beta$-sheet-rich structural features found in seminal amyloid species such as semen-derived enhancer of virus infection (SEVI) as well as in other amyloid aggregates [100]. The small molecule aminoquinoline surfen is another example of a SEVI-binding molecule that inhibits the interaction between SEVI and cellular and viral surfaces [101].

\section{Concluding remarks}

There are many targets that have been evaluated for treating HIV and for which many thousands of compounds have been tested in vitro (Table 2). We have briefly summarized newer targets for HIV that do not have FDA-approved drugs on the market to address this virus (Table 1). These targets represent a broad array of predominantly host proteins that could all be targeted with small molecules. Most of these targets have received little or no attention from the drug discovery community yet could be compelling even with all the attendant limitations of toxicity over long-term use. There is still a considerable need to find new drugs to address this virus and to create new intellectual property. Some of these newer drug targets are also useful for developing drugs for other viruses and could in turn represent 
broad-spectrum antiviral targets. The value of these targets will be determined in due course as drugs targeting them are approved by the FDA.

\section{Acknowledgments}

We kindly acknowledge NIH NINDS 1R01NS102164-01 and RFBR 17-54-30007. Research reported in this publication was supported by the National Institute of Neurological Disorders and Stroke of the National Institutes of Health under award number 1R01NS102164-01. Dr Thomas Lane and Ms Kim Zorn are kindly acknowledged for assistance with HIV research and preparing Table 1. Dr Mohamed Nasr is thanked for assistance with obtaining the NIAID ChemDB HIV, Opportunistic Infection and Tuberculosis Therapeutics Database.

\section{References}

1. Sharp PM and Hahn BH (2011) Origins of HIV and the AIDS pandemic. Cold Spring Harb. Perspect. Med 1, a006841 [PubMed: 22229120]

2. WHO. (2018) HIV/AIDS

3. Kinch MS and Patridge E (2014) An analysis of FDA-approved drugs for infectious disease: HIV/ AIDS drugs. Drug Discov. Today 19, 1510-1513 [PubMed: 24880109]

4. Tan IL and McArthur JC (2012) HIV-associated neurological disorders: a guide to pharmacotherapy. CNS Drugs 26, 123-134 [PubMed: 22201342]

5. Kolson D and Buch S (2013) More than two HANDs to tango. J. Neuroimmune Pharmacol 8, 10511054 [PubMed: 24233518]

6. Kraft-Terry SD et al. (2009) A coat of many colors: neuroimmune crosstalk in human immunodeficiency virus infection. Neuron 64, 133-145 [PubMed: 19840555]

7. Bertrand L et al. (2016) Solving the blood-brain barrier challenge for the effective treatment of HIV replication in the central nervous system. Curr. Pharm. Des 22, 5477-5486 [PubMed: 27464720]

8. Rumbaugh JA et al. (2008) Developing neuroprotective strategies for treatment of HIV-associated neurocognitive dysfunction. Fut. HIV Ther 2, 271-280

9. Saylor D et al. (2016) HIV-associated neurocognitive disorder - pathogenesis and prospects for treatment. Nat. Rev. Neurol 12, 309 [PubMed: 27080521]

10. Esposito F et al. (2012) HIV-1 reverse transcriptase still remains a new drug target: structure, function, classical inhibitors, and new inhibitors with innovative mechanisms of actions. Mol. Biol. Int 2012, 586401 [PubMed: 22778958]

11. Friedrich BM et al. (2011) Host factors mediating HIV-1 replication. Virus Res 161, 101-114 [PubMed: 21871504]

12. Hutter G et al. (2009) Long-term control of HIV by CCR5 Delta32/Delta32 stem-cell transplantation. N. Engl. J. Med 360, 692-698 [PubMed: 19213682]

13. Tebas P et al. (2014) Gene editing of CCR5 in autologous CD4 T cells of persons infected with HIV. N. Engl. J. Med 370, 901-910 [PubMed: 24597865]

14. Lai MM (1998) Cellular factors in the transcription and replication of viral RNA genomes: a parallel to DNA-dependent RNA transcription. Virology 244, 1-12 [PubMed: 9581772]

15. Rolando M and Buchrieser C (2014) Legionella pneumophila type IV effectors hijack the transcription and translation machinery of the host cell. Trends Cell Biol 24, 771-778 [PubMed: 25012125]

16. Park RJ et al. (2017) A genome-wide CRISPR screen identifies a restricted set of HIV host dependency factors. Nat. Genet 49, 193-203 [PubMed: 27992415]

17. Farzan M et al. (1999) Tyrosine sulfation of the amino terminus of CCR5 facilitates HIV-1 entry. Cell 96, 667-676 [PubMed: 10089882]

18. van den Boom J et al. (2012) 3'-Phosphoadenosine 5' -phosphosulfate (PAPS) synthases, naturally fragile enzymes specifically stabilized by nucleotide binding. J. Biol. Chem 287, 17645-17655 [PubMed: 22451673]

19. Kamiyama S et al. (2003) Molecular cloning and identification of 3'-phosphoadenosine 5'phosphosulfate transporter. J. Biol. Chem 278, 25958-25963 [PubMed: 12716889] 
20. Seibert C et al. (2002) Tyrosine sulfation of CCR5 N-terminal peptide by tyrosylprotein sulfotransferases 1 and 2 follows a discrete pattern and temporal sequence. Proc. Natl. Acad. Sci. U. S. A 99, 11031-11036 [PubMed: 12169668]

21. Neira JL (2009) Biophysical and structural studies on the capsid protein of the human immunodeficiency virus type 1: a new drug target? ScientificWorldJournal 9, 404-419 [PubMed: 19484162]

22. Cheng $\mathrm{N}$ et al. (2014) Development of a novel screening strategy designed to discover a new class of HIV drugs. J. Lab. Autom 19, 297-303 [PubMed: 24305957]

23. Tian YS et al. (2013) Discovery of novel low-molecular-weight HIV-1 inhibitors interacting with cyclophilin A using in silico screening and biological evaluations. J. Mol. Model 19, 465-475 [PubMed: 22949064]

24. Smith PF et al. (2007) Phase I and II study of the safety, virologic effect, and pharmacokinetics/ pharmacodynamics of single-dose 3-o-(3',3'-dimethylsuccinyl)betulinic acid (bevirimat) against human immunodeficiency virus infection. Antimicrob. Agents Chemother 51, 3574-3581 [PubMed: 17638699]

25. Wang W et al. (2017) Inhibition of HIV-1 maturation via small-molecule targeting of the aminoterminal domain in the viral capsid protein. J. Virol 91, e02155-16 [PubMed: 28202766]

26. Lemke CT et al. (2012) Distinct effects of two HIV-1 capsid assembly inhibitor families that bind the same site within the N-terminal domain of the viral CA protein. J. Virol 86, 6643-6655 [PubMed: 22496222]

27. Sokolskaja E et al. (2004) Target cell cyclophilin A modulates human immunodeficiency virus type 1 infectivity. J. Virol 78, 12800-12808 [PubMed: 15542632]

28. Li J et al. (2009) Discovery of dual inhibitors targeting both HIV-1 capsid and human cyclophilin A to inhibit the assembly and uncoating of the viral capsid. Bioorg. Med. Chem 17, 3177-3188 [PubMed: 19328002]

29. Liu C et al. (2016) Cyclophilin A stabilizes the HIV-1 capsid through a novel non-canonical binding site. Nat. Commun 7, 10714 [PubMed: 26940118]

30. Freedman RB (1989) Protein disulfide isomerase: multiple roles in the modification of nascent secretory proteins. Cell 57, 1069-1072 [PubMed: 2544299]

31. Gallina A et al. (2002) Inhibitors of protein-disulfide isomerase prevent cleavage of disulfide bonds in receptor-bound glycoprotein 120 and prevent HIV-1 entry. J. Biol. Chem 277, 50579-50588 [PubMed: 12218051]

32. Barbouche R et al. (2003) Protein-disulfide isomerase-mediated reduction of two disulfide bonds of HIV envelope glycoprotein 120 occurs post-CXCR4 binding and is required for fusion. J. Biol. Chem 278, 3131-3136 [PubMed: 12218052]

33. Tsibris JC et al. (1989) Selective inhibition of protein disulfide isomerase by estrogens. J. Biol. Chem 264, 13967-13970 [PubMed: 2668279]

34. Khan MM et al. (2011) Discovery of a small molecule PDI inhibitor that inhibits reduction of HIV-1 envelope glycoprotein gp120. ACS Chem. Biol 6, 245-251 [PubMed: 21121641]

35. Bi S et al. (2011) Galectin-9 binding to cell surface protein disulfide isomerase regulates the redox environment to enhance T-cell migration and HIV entry. Proc. Natl. Acad. Sci. U. S. A 108, 10650-10655 [PubMed: 21670307]

36. Curreli F et al. (2016) Design, synthesis and evaluation of small molecule CD4-mimics as entry inhibitors possessing broad spectrum anti-HIV-1 activity. Bioorg. Med. Chem 24, 5988-6003 [PubMed: 27707628]

37. Melillo B et al. (2016) Small-molecule CD4-mimics: structure-based optimization of HIV-1 entry inhibition. ACS Med. Chem. Lett 7, 330-334 [PubMed: 26985324]

38. Nekhai S et al. (2013) Role of cellular iron and oxygen in the regulation of HIV-1 infection. Future Virol 8, 301-311 [PubMed: 23678366]

39. Liu Y et al. (2018) Lysine-specific demethylase 1 cooperates with BRAF-histone deacetylase complex 80 to enhance HIV-1 Tat-mediated transactivation. Virus Genes 54, 662-671 [PubMed: 30105631]

40. Lin X et al. (2017) Protein phosphatase-1-targeted small molecules, iron chelators and curcumin analogs as HIV-1 antivirals. Curr. Pharm. Des 23, 4122-4132 [PubMed: 28677499] 
41. Boyer PL et al. (2018) Developing and evaluating inhibitors against the RNase H active site of HIV-1 reverse transcriptase. J. Virol 92, e02203-17 [PubMed: 29643235]

42. Cuzzucoli Crucitti G et al. (2015) Structure-activity relationship of pyrrolyl diketo acid derivatives as dual inhibitors of HIV-1 integrase and reverse transcriptase ribonuclease H domain. J. Med. Chem 58, 1915-1928 [PubMed: 25629256]

43. Corona A et al. (2017) Design, synthesis and antiviral evaluation of novel heteroarylcarbothioamide derivatives as dual inhibitors of HIV-1 reverse transcriptase-associated RNase $\mathrm{H}$ and RDDP functions. Pathog. Dis 75, 78

44. Blokken J et al. (2017) Protein-protein and protein-chromatin interactions of LEDGF/p75 as novel drug targets. Drug Discov. Today Technol 24, 25-31 [PubMed: 29233296]

45. Bertoletti $\mathrm{F}$ et al. (2012) Tyrosine kinases as essential cellular cofactors and potential therapeutic targets for human immunodeficiency virus infection. Cell Mol. Biol 58, 31-43 [PubMed: 23273189]

46. Phipps DJ et al. (1996) HIV infection in vitro enhances the activity of Src-family protein tyrosine kinases. AIDS 10, 1191-1198 [PubMed: 8883579]

47. McCarthy SD et al. (2016) c-SRC protein tyrosine kinase regulates early HIV-1 infection postentry. AIDS 30, 849-858 [PubMed: 26807966]

48. Percario ZA et al. (2015) Nef, the shuttling molecular adaptor of HIV, influences the cytokine network. Cytokine Growth Factor Rev 26, 159-173 [PubMed: 25529283]

49. Sauter D and Kirchhoff F (2018) Multilayered and versatile inhibition of cellular antiviral factors by HIV and SIV accessory proteins. Cytokine Growth Factor Rev 40, 3-12 [PubMed: 29526437]

50. Pereira EA and daSilva LL (2016) HIV-1 Nef: taking control of protein trafficking. Traffic 17, 976-996 [PubMed: 27161574]

51. Selby MJ et al. (1989) Structure, sequence, and position of the stem-loop in tar determine transcriptional elongation by tat through the HIV-1 long terminal repeat. Genes Dev 3, 547-558 [PubMed: 2470647]

52. Deeks SG et al. (2013) The end of AIDS: HIV infection as a chronic disease. Lancet 382, 15251533 [PubMed: 24152939]

53. Razooky BS et al. (2015) A hardwired HIV latency program. Cell 160, 990-1001 [PubMed: 25723172]

54. Karn J (2011) The molecular biology of HIV latency: breaking and restoring the Tat-dependent transcriptional circuit. Curr. Opin. HIV AIDS 6, 4-11 [PubMed: 21242887]

55. Ghose $\mathrm{R}$ et al. (2001) Induction of TAK (cyclin T1/P-TEFb) in purified resting CD4(+) T lymphocytes by combination of cytokines. J. Virol 75, 11336-11343 [PubMed: 11689614]

56. Kinoshita S et al. (1998) Host control of HIV-1 parasitism in T cells by the nuclear factor of activated T cells. Cell 95, 595-604 [PubMed: 9845362]

57. Nabel G and Baltimore D (1987) An inducible transcription factor activates expression of human immunodeficiency virus in T cells. Nature 326, 711-713 [PubMed: 3031512]

58. Tyagi M and Karn J (2007) CBF-1 promotes transcriptional silencing during the establishment of HIV-1 latency. EMBO J 26, 4985-4995 [PubMed: 18007589]

59. He G and Margolis DM (2002) Counterregulation of chromatin deacetylation and histone deacetylase occupancy at the integrated promoter of human immunodeficiency virus type 1 (HIV-1) by the HIV-1 repressor YY1 and HIV-1 activator Tat. Mol. Cell Biol 22, 2965-2973 [PubMed: 11940654]

60. Lenasi T et al. (2008) Transcriptional interference antagonizes proviral gene expression to promote HIV latency. Cell Host Microbe 4, 123-133 [PubMed: 18692772]

61. Gao WY et al. (1993) Low levels of deoxynucleotides in peripheral blood lymphocytes: a strategy to inhibit human immunodeficiency virus type 1 replication. Proc. Natl. Acad. Sci. U. S. A 90, 8925-8928 [PubMed: 7692440]

62. Mahmoudi T et al. (2006) The SWI/SNF chromatin-remodeling complex is a cofactor for Tat transactivation of the HIV promoter. J. Biol. Chem 281, 19960-19968 [PubMed: 16687403]

63. Treand C et al. (2006) Requirement for SWI/SNF chromatin-remodeling complex in Tat-mediated activation of the HIV-1 promoter. EMBO J 25, 1690-1699 [PubMed: 16601680] 
64. Van Lint C et al. (2013) HIV-1 transcription and latency: an update. Retrovirology 10, 67 [PubMed: 23803414]

65. Cary DC et al. (2016) Molecular mechanisms of HIV latency. J. Clin. Invest 126, 448-454 [PubMed: 26731470]

66. Yukl S et al. (2009) Latently-infected CD4+ T cells are enriched for HIV-1 Tat variants with impaired transactivation activity. Virology 387, 98-108 [PubMed: 19268337]

67. Mousseau G et al. (2015) The Tat inhibitor didehydro-cortistatin A prevents HIV-1 reactivation from latency. MBio 6, e00465 [PubMed: 26152583]

68. Kessing CF et al. (2017) In vivo suppression of HIV rebound by didehydrocortistatin A, a "blockand-lock" strategy for HIV-1 treatment. Cell Rep 21, 600-611 [PubMed: 29045830]

69. Lambert AA et al. (2013) Dendritic cell immunoreceptor is a new target for anti-AIDS drug development: identification of DCIR/HIV-1 inhibitors. PLoS One 8, e67873 [PubMed: 23874461]

70. Besnard E et al. (2016) The mTOR complex controls HIV latency. Cell Host Microbe 20, 785-797 [PubMed: 27978436]

71. Heredia A et al. (2008) Reduction of CCR5 with low-dose rapamycin enhances the antiviral activity of vicriviroc against both sensitive and drug-resistant HIV-1. Proc. Natl. Acad. Sci. U. S. A 105, 20476-20481 [PubMed: 19075241]

72. Gavegnano C et al. (2014) Ruxolitinib and tofacitinib are potent and selective inhibitors of HIV-1 replication and virus reactivation in vitro. Antimicrob. Agents Chemother 58, 1977-1986 [PubMed: 24419350]

73. Gavegnano C et al. (2017) Novel mechanisms to inhibit HIV reservoir seeding using Jak inhibitors. PLoS Pathog 13, e1006740 [PubMed: 29267399]

74. Zheng Y et al. (2011) Host protein Ku70 binds and protects HIV-1 integrase from proteasomal degradation and is required for HIV replication. J. Biol. Chem 286, 17722-17735 [PubMed: 21454661]

75. Pagans S et al. (2005) SIRT1 regulates HIV transcription via Tat deacetylation. PLoS Biol 3, e41 [PubMed: 15719057]

76. Kwon HS et al. (2008) Human immunodeficiency virus type 1 Tat protein inhibits the SIRT1 deacetylase and induces T cell hyperactivation. Cell Host Microbe 3, 158-167 [PubMed: 18329615]

77. Hardie DG (2007) AMP-activated/SNF1 protein kinases: conserved guardians of cellular energy. Nat. Rev. Mol. Cell Biol 8, 774-785 [PubMed: 17712357]

78. Sanz P (2008) AMP-activated protein kinase: structure and regulation. Curr. Protein Pept. Sci 9 , 478-492 [PubMed: 18855699]

79. Zhang HS and Wu MR (2009) SIRT1 regulates Tat-induced HIV-1 transactivation through activating AMP-activated protein kinase. Virus Res 146, 51-57 [PubMed: 19720090]

80. Ara A et al. (2017) Mechanism of enhanced HIV restriction by virion coencapsidated cytidine deaminases APOBEC3F and APOBEC3G. J. Virol 91, e02230-16 [PubMed: 27881650]

81. Izumi T et al. (2008) Cytidine deaminases as a weapon against retroviruses and a new target for antiviral therapy. Mini Rev. Med. Chem 8, 231-238 [PubMed: 18336343]

82. Lafferty MK et al. (2010) CCR6 ligands inhibit HIV by inducing APOBEC3G. Blood 115, 15641571 [PubMed: 20023216]

83. Lafferty MK et al. (2017) Human beta defensin 2 selectively inhibits HIV-1 in highly permissive CCR6(+)CD4(+) T cells. Viruses 9, doi: 10.3390/v9050111

84. Wu G et al. (2018) Synthesis and structure-activity relationship studies of MI-2 analogues as MALT1 inhibitors. Bioorg. Med. Chem 26, 3321-3344 [PubMed: 29751989]

85. Schlapbach A et al. (2018) $\mathrm{N}$-aryl-piperidine-4-carboxamides as a novel class of potent inhibitors of MALT1 proteolytic activity. Bioorg. Med. Chem. Lett 28, 2153-2158 [PubMed: 29759726]

86. Li H et al. (2016) Short communication: preferential killing of HIV latently infected CD4(+) T cells by MALT1 inhibitor. AIDS Res. Hum. Retroviruses 32, 174-177 [PubMed: 26728103]

87. Suresh R and Mosser DM (2013) Pattern recognition receptors in innate immunity, host defense, and immunopathology. Adv. Physiol. Educ 37, 284-291 [PubMed: 24292903] 
88. Altfeld M and Gale M Jr (2015) Innate immunity against HIV-1 infection. Nat. Immunol 16, 554 562 [PubMed: 25988887]

89. Swaminathan G et al. (2012) A role for microRNA-155 modulation in the anti-HIV-1 effects of Toll-like receptor 3 stimulation in macrophages. PLoS Pathog 8, e1002937 [PubMed: 23028330]

90. Verani A et al. (1997) C-C chemokines released by lipopolysaccharide (LPS)-stimulated human macrophages suppress HIV-1 infection in both macrophages and T cells. J. Exp. Med 185, 805816 [PubMed: 9120386]

91. Cocchi F et al. (1995) Identification of RANTES, MIP-1 alpha, and MIP-1 beta as the major HIVsuppressive factors produced by CD8+ T cells. Science 270, 1811-1815 [PubMed: 8525373]

92. Collins RA and $\mathrm{Ng} \mathrm{TB}$ (1997) Polysaccharopeptide from Coriolus versicolor has potential for use against human immunodeficiency virus type 1 infection. Life Sci 60, PL383-387 [PubMed: 9194694]

93. Rodriguez-Valentin M et al. (2018) Naturally derived anti-HIV polysaccharide peptide (PSP) triggers a Toll-like receptor 4-dependent antiviral immune response. J. Immunol. Res 2018, 8741698 [PubMed: 30116757]

94. Kawaguchi A et al. (2012) YB-1 functions as a porter to lead influenza virus ribonucleoprotein complexes to microtubules. J. Virol 86, 11086-11095 [PubMed: 22855482]

95. Ansari SA et al. (1999) Interaction of YB-1 with human immunodeficiency virus type 1 Tat and TAR RNA modulates viral promoter activity. J. Gen. Virol 80, 2629-2638 [PubMed: 10573156]

96. Weydert $\mathrm{C}$ et al. (2018) Y-box-binding protein 1 supports the early and late steps of HIV replication. PLoS One 13, e0200080 [PubMed: 29995936]

97. Lobaina Y and Perera Y (2019) Implication of B23/nucleophosmin in viral infections, potential uses of B23/NPM1 inhibitors as antiviral therapy. Infect. Disord. Drug Targets 19, 2-16 [PubMed: 29589547]

98. Sheik DA et al. (2017) Natural seminal amyloids as targets for development of synthetic inhibitors of HIV transmission. Acc. Chem. Res 50, 2159-2166 [PubMed: 28809479]

99. Hauber I et al. (2009) The main green tea polyphenol epigallocatechin-3-gallate counteracts semen-mediated enhancement of HIV infection. Proc. Natl. Acad. Sci. U. S. A 106, 9033-9038 [PubMed: 19451623]

100. Olsen JS et al. (2010) Amyloid-binding small molecules efficiently block SEVI (semen-derived enhancer of virus infection)- and semen-mediated enhancement of HIV-1 infection. J. Biol. Chem 285, 35488-35496 [PubMed: 20833717]

101. Roan NR et al. (2010) Aminoquinoline surfen inhibits the action of SEVI (semen-derived enhancer of viral infection). J. Biol. Chem 285, 1861-1869 [PubMed: 19897482]

102. Zhou W et al. (2017) A fluorescence-based high-throughput assay to identify inhibitors of tyrosylprotein sulfotransferase activity. Biochem. Biophys. Res. Commun 482, 1207-1212 [PubMed: 27923653]

103. Byrne DP et al. (2018) New tools for evaluating protein tyrosine sulfation: tyrosylprotein sulfotransferases (TPSTs) are novel targets for RAF protein kinase inhibitors. Biochem. J 475, 2435-2455 [PubMed: 29934490]

104. Sticht J et al. (2005) A peptide inhibitor of HIV-1 assembly in vitro. Nat. Struct. Mol. Biol 12, 671-677 [PubMed: 16041387]

105. Thenin-Houssier S et al. (2016) Ebselen, a small-molecule capsid inhibitor of HIV-1 replication. Antimicrob. Agents Chemother 60, 2195-2208 [PubMed: 26810656]

106. Romashov LV and Ananikov VP (2016) Synthesis of HIV-1 capsid protein assembly inhibitor (CAP-1) and its analogues based on a biomass approach. Org. Biomol. Chem 14, 10593-10598 [PubMed: 27714265]

107. Fujioka T et al. (1994) Anti-AIDS agents, 11. Betulinic acid and platanic acid as anti-HIV principles from Syzigium claviflorum, and the anti-HIV activity of structurally related triterpenoids. J. Nat. Prod 57, 243-247 [PubMed: 8176401]

108. George A et al. (2018) 1,2,3,4-Tetrahydroisoquinolines as inhibitors of HIV-1 integrase and human LEDGF/p75 interaction. Chem. Biol. Drug Des 91, 1133-1140 [PubMed: 29405651] 
109. Zhang FH et al. (2017) Discovery of novel 3-hydroxypicolinamides as selective inhibitors of HIV-1 integrase-LEDGF/p75 interaction. Eur. J. Med. Chem 125, 1051-1063 [PubMed: 27810592]

110. Patel PA et al. (2016) Indole-based allosteric inhibitors of HIV-1 integrase. Bioorg. Med. Chem. Lett 26, 4748-4752 [PubMed: 27568085]

111. Smithgall TE and Thomas G (2013) Small molecule inhibitors of the HIV-1 virulence factor, Nef. Drug Discov. Today Technol. 10, e523-529 [PubMed: 24451644] 


\section{Highlights:}

- $\quad$ HIV kills close to one million people

- $\quad$ There is a need for new treatments to address drug resistance

- There are many newer targets that could be targeted with small molecules

- Over 20 of these targets are discussed with references to work, to date

- $\quad$ Some of these targets could also lead to broad-spectrum antivirals 


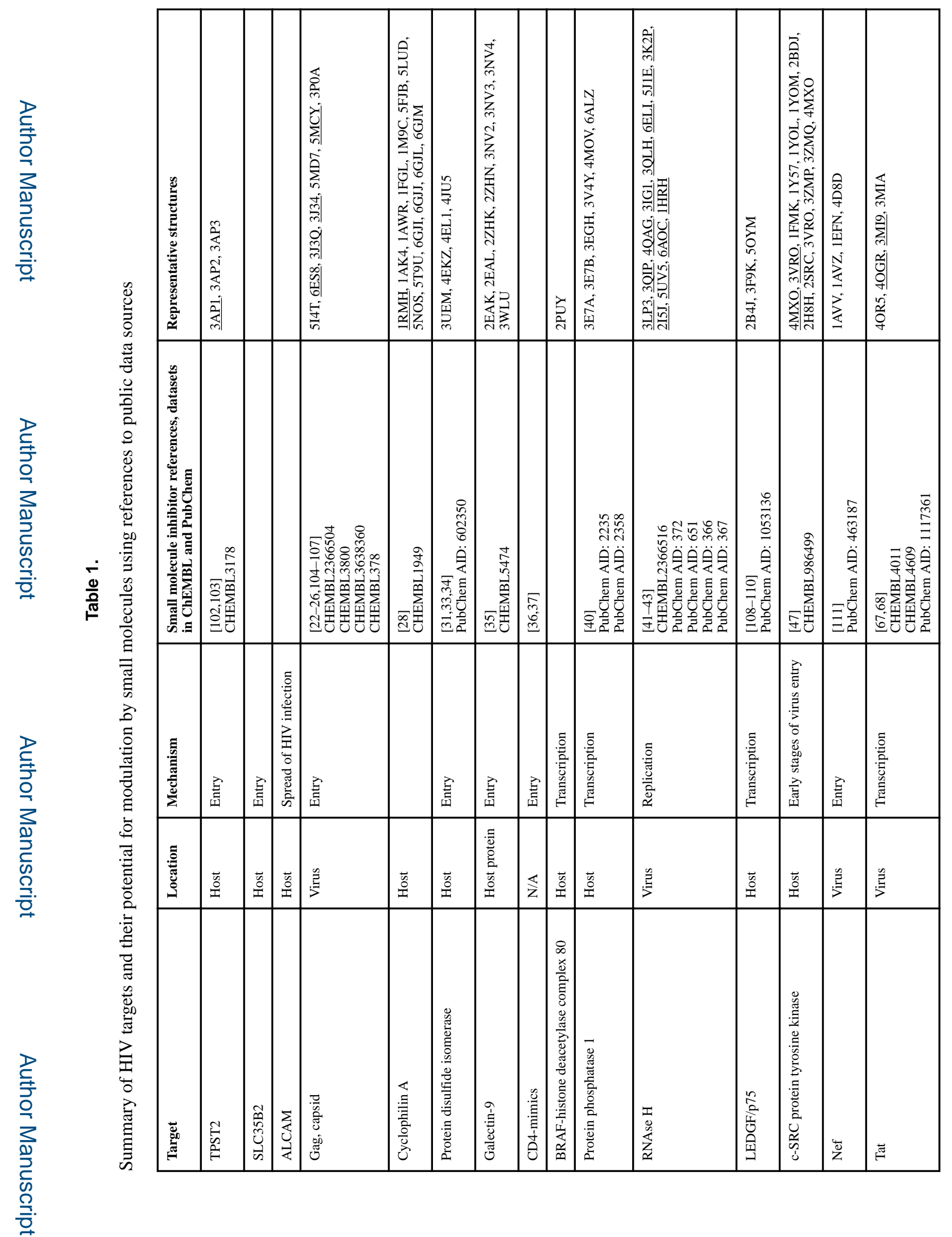

Drug Discov Today. Author manuscript; available in PMC 2020 May 01. 

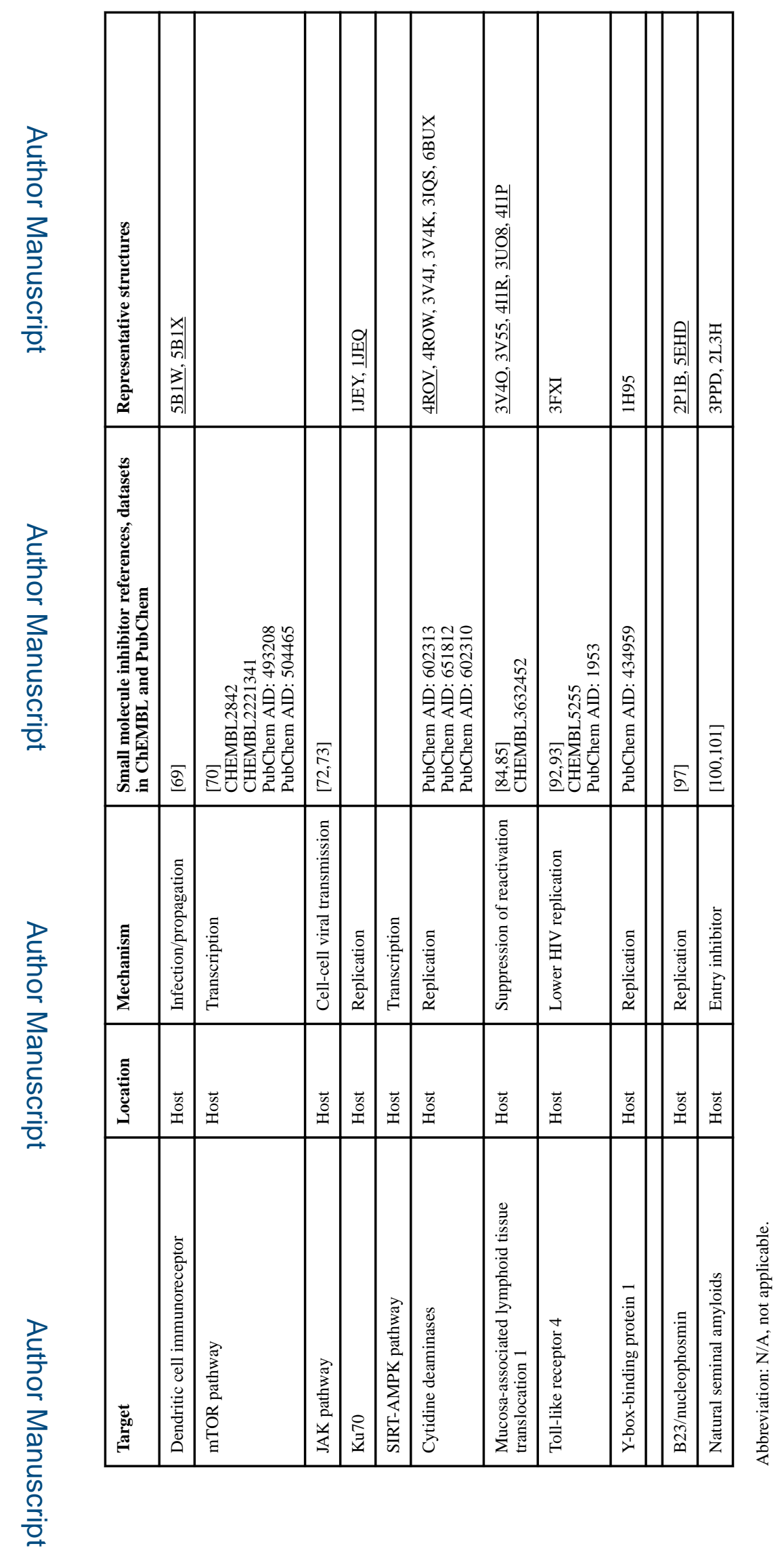

Drug Discov Today. Author manuscript; available in PMC 2020 May 01. 
Puhl et al.

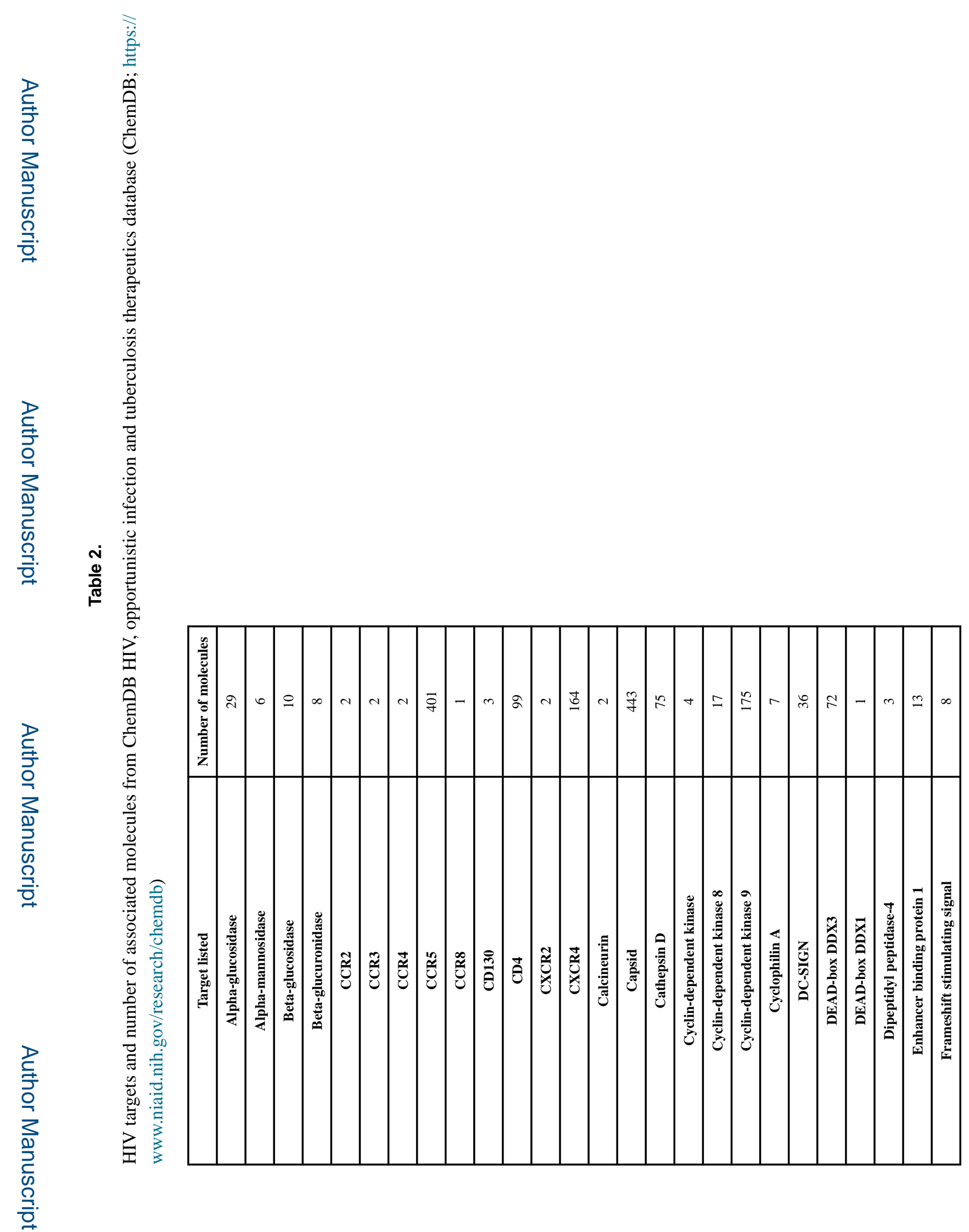

Drug Discov Today. Author manuscript; available in PMC 2020 May 01. 


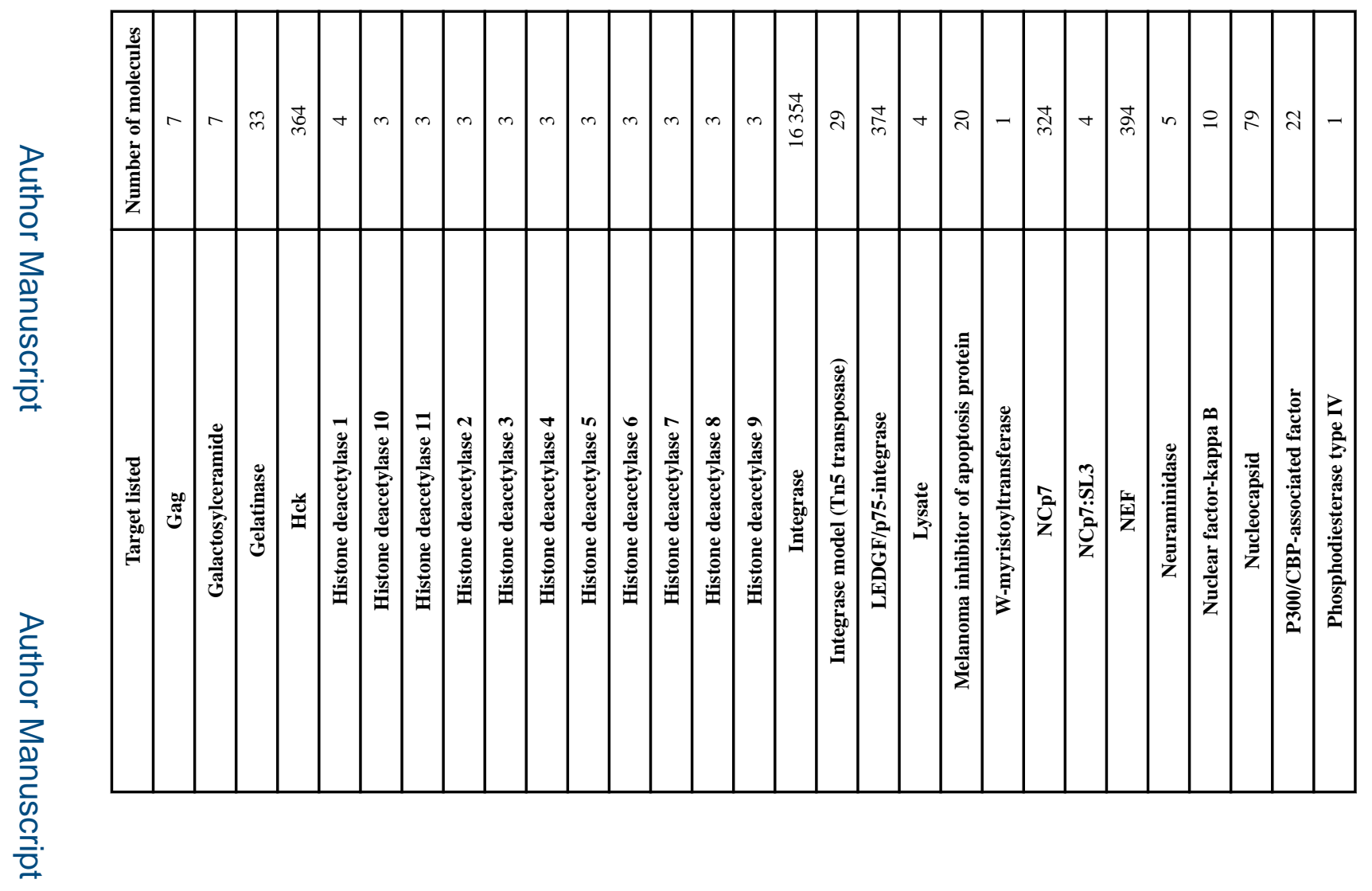

롤

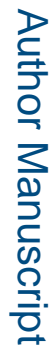




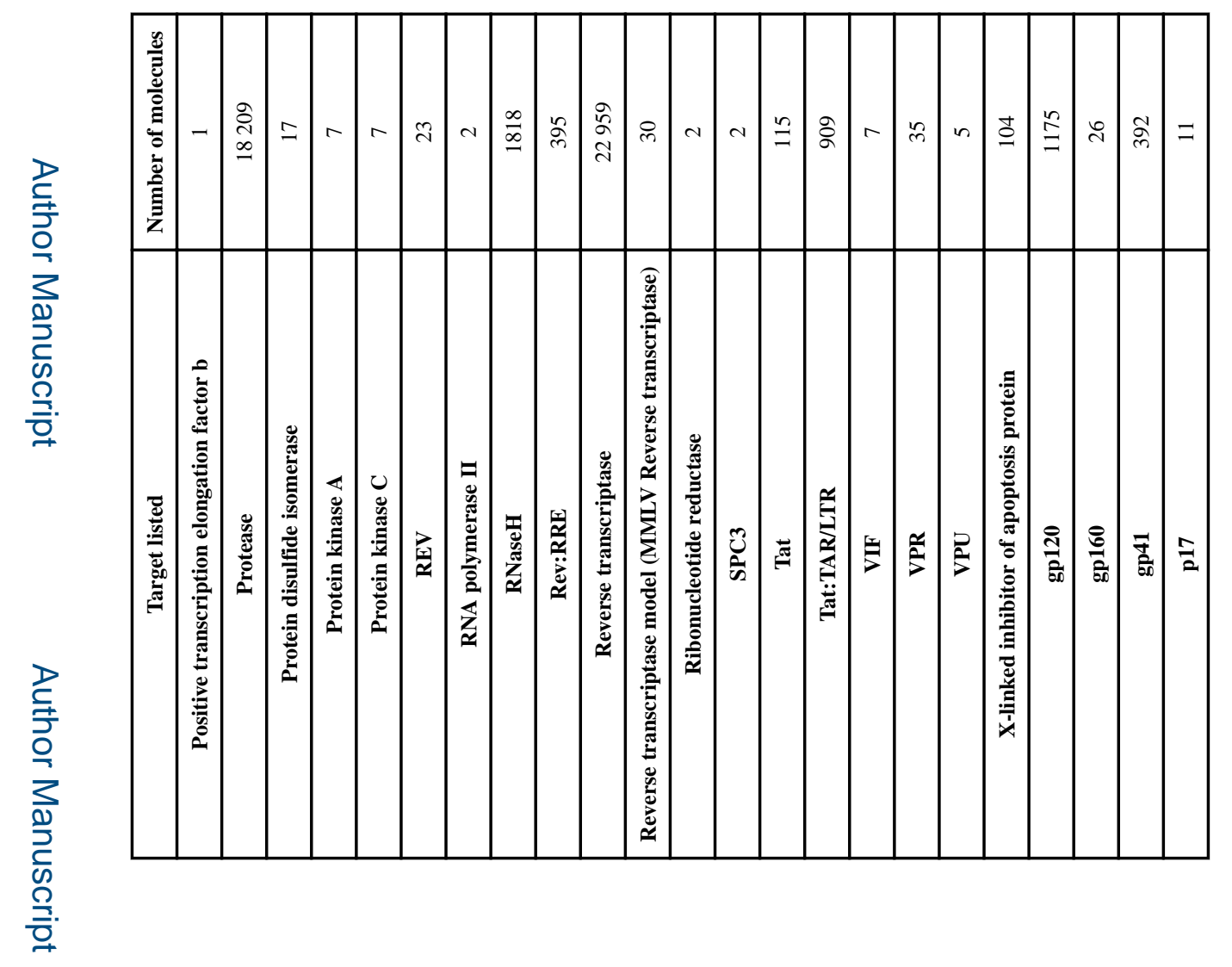

로을

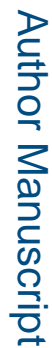

